\title{
How has the distribution of the population in local cities been changing over time according to the frequency of railways and tramways?
}

\author{
M. Nagao ${ }^{1}$, D. Nakagawa ${ }^{1}$, R. Matsunaka ${ }^{1}$, T. Oba $^{1}$ \\ \& A. Mochizuki ${ }^{2}$ \\ ${ }^{I}$ Graduate School of Engineering, Kyoto University, Japan \\ ${ }^{2}$ Urban Renaissance Agency, Japan
}

\begin{abstract}
Motorization has become widespread in local cities in Japan. Therefore, city functions and residents have been dispersed to suburbs and daily life has become difficult without private cars. Recently, the concept of a compact city has been attracting attention. It is said that one of the most important keys to realizing a compact city is to develop very convenient public transportation. However, in local cities in Japan, although there are public transportation networks, they are not effectively used because service frequency is very low. This research analyzed the present distributions of populations around stations and how they have changed over time by the levels of service frequencies of railways and tramways in all local cities in Japan. More specifically, at first, the transportation frequencies over railways and tramways and changes in the distribution of population of all local cities in Japan over time were investigated. Then the degree of service frequencies of stations in the public transport system, railways and tramways, their affect on the present distribution of the population around the stations and their changes over time were analyzed.
\end{abstract}

Keywords: service frequency, railway, tramway, distribution of the population.

\section{Introduction}

Motorization has become widespread in local cities in Japan. Therefore, city functions and residents have been dispersed to suburbs and daily life has become difficult without private cars. Recently, the concept of a compact city has been attracting attention. It is said that one of the most important keys to realizing a 
compact city is to develop very convenient public transportation. However, in local cities in Japan, although there are public transportation networks, they are not effectively used because service frequency is very low. There is no clear data to support the development of very convenient public transportation systems that could increase the population of surrounding areas and help to build a compact city around them.

The purpose of this paper is to verify the distribution of the population of 134 local cities in Japan and how they have been changing over time according to the frequency of public transportation, including railways and tramways. More specifically, at first, the transportation frequencies over railways and tramways and changes in the distribution of population of all local cities in Japan over time were investigated. Then the degree of service frequencies of stations in the public transport system, railways and tramways, their affect on the present distribution of the population around the stations and their changes over time were analyzed.

\section{Reference review}

As for study focused on the relationship between the convenience of public transport and urban structure, Mochizuki et al. [1] have clarified the effect of the Toyama Light Rail, the first-ever full-scale Light Rail Transit System in Japan and the activities around its stations. Oba et al. [2] have verified that the populations around railway stations are decreasing and the populations in the areas separated from the stations are increasing in local cities in Japan. Miyata et al. [3] evaluated the changes of populations in the cities, towns and villages along railway lines caused by the abolishment of local railway, and examined its effect on local societies. Nakagawa et al. [4] verified the effect of railway development on the populations in local cities, towns and villages from population changes and the timings of railway development. Hass-Klau et al. [5], targeting cities in countries in Europe and North America that have introduced Light Rail Transit, extracted success factors by analyzing the characteristics of cities and areas along the lines including the service frequencies at peak times. Tsuji et al. [6], targeting the cities having tramways in Japan, clarified the relationship between the compactness of cities and tramways. Sabo [7] and Kaido [8] evaluated the compactness of cities based upon actual statistical data.

Compared with these studies, the feature of this study is that it targeted the stations of railways and tramways in all local cities in Japan, and performed an analysis based upon precise service frequency data by timetable, and then conducted an analysis on a micro-scale for such station vicinities.

\section{Analytical method}

\subsection{Definition of targeted stations of railways and tramways}

The cities in Japan with a population over one hundred thousand as of 2005 were targeted for this study. Among them, the cities in the large city areas such as: 
Tokyo, Osaka and Nagoya and those having no railways and tramways in 2005 were excluded from the targets of this study. In this way, 134 local cities were extracted. They include Sapporo, where the Winter Olympics were held in 1972, Himeji having Himeji Castle, a World Heritage Site, and various other cities around Japan. Fig. 1 shows the number of these cities based on the size of their population.

This study targeted the stations of railways and tramways that existed in these local cities as of 2005. There were 2,338 stations in total in these 134 local cities, and among these, there were 1,903 railway stations and 435 tramway stations.

\subsection{Calculation method of service frequencies}

In this study, an indicator to express the convenience of railways and tramways in Japan, the service frequency at the off peak time at each station was used.

To begin with, the number of trains leaving stations during 9:00-16:59 was counted based upon the 2005 timetable and the level of the number of trains was counted for each line. For the station connected with other numerical lines, the level of service for all lines individually were added as a whole to calculate the

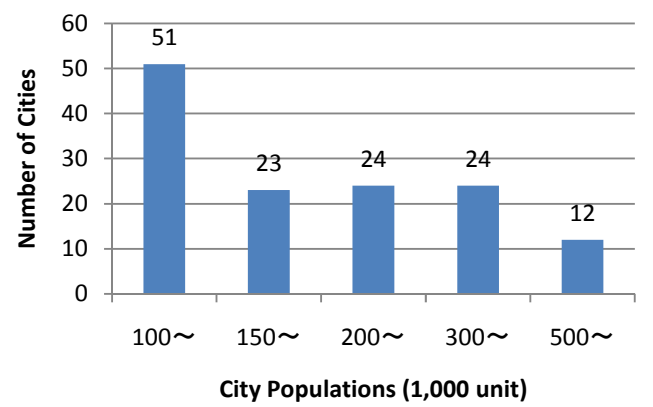

Figure 1: $\quad$ Number of cities by population scale.
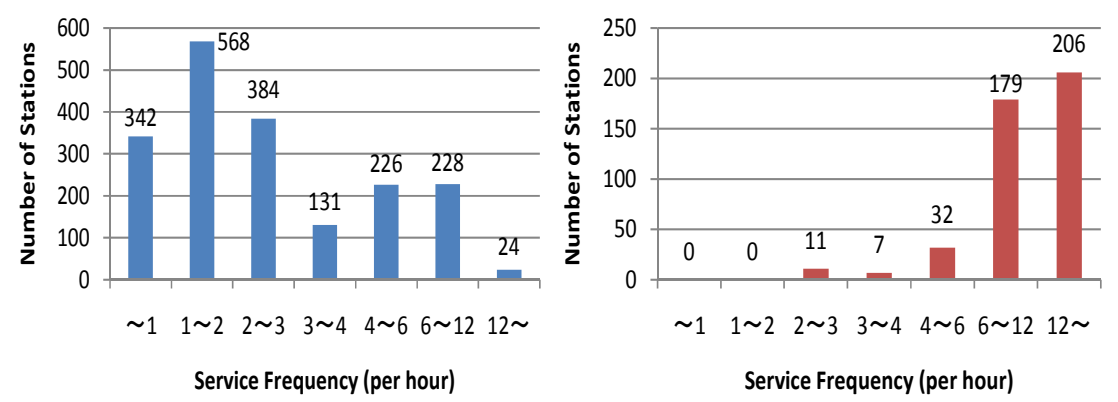

Figure 2: Number of stations for each service frequency classification (left: railway, right: tramway). 
station total. Then, the total level of service was divided by the off-peak hours, and the service frequencies (service/h) were thus obtained.

After calculating the service frequency of each targeted station, the stations of railways and tramways were classified into seven frequency classifications by the level of frequency. Fig. 2 shows the number of railway stations and tramway stations in the 134 local cities for each service frequency classification. The average service frequency of targeted stations is 2.98 service/hour for railway stations and 11.46 service/hour for tramway stations. There are many stations with high service frequency.

\subsection{Method of calculating population around the influence area of a station}

As for the populations of influence areas, all stations within a $500 \mathrm{~m}$ radius of a particular station for a total of 134 local cities were calculated. For this calculation, the grid data of the national population census of 1995, 2000 and 2005 were used.

For the grids crossing over the boundary between the influence area of a station and another one, the population was calculated by proportionally dividing it based upon the area ratio of the influence area and outside of it.

\section{Relationship between the distribution of population around the station and its service frequency}

\subsection{Relationship between the distributions of population surrounding all railway and tramway stations and the service frequencies}

The populations of the influence area of stations of both railways and tramways in 1995, 2000 and 2005 were calculated for each service frequency classification. Table 1 shows the population per railway station and Table 2 shows that of tramway stations.

As shown in Figs. 3 and 4, the stations with higher service frequencies tend to have larger population in their influence areas. Among them, there are large

Table 1: $\quad$ Population of the influence area of the station for each service frequency classification (all railway stations).

\begin{tabular}{c|r|rrr}
\hline $\begin{array}{c}\text { Service } \\
\text { Frequency }\end{array}$ & $\begin{array}{c}\text { Number } \\
\text { of } \\
\text { (per hour) }\end{array}$ & \multicolumn{3}{|c}{$\begin{array}{c}\text { Population of the influence area } \\
\text { of the Station }\end{array}$} \\
\cline { 3 - 5 } & Stations & \multicolumn{1}{|c}{1995} & 2000 & 2005 \\
\hline$\sim 1$ & 342 & 780 & 773 & 756 \\
$1 \sim 2$ & 568 & 1,564 & 1,556 & 1,529 \\
$2 \sim 3$ & 384 & 2,399 & 2,403 & 2,402 \\
$3 \sim 4$ & 131 & 2,933 & 2,959 & 2,987 \\
$4 \sim 6$ & 226 & 3,227 & 3,267 & 3,330 \\
$6 \sim 12$ & 228 & 4,593 & 4,737 & 4,967 \\
$12 \sim$ & 24 & 3,852 & 3,911 & 4,240 \\
\hline Total & 1,903 & 2,275 & 2,297 & 2,327 \\
\hline
\end{tabular}


Table 2: $\quad$ Population of the influence area of the station for each service frequency classification (all tramway stations).

\begin{tabular}{c|r|rrr}
\hline $\begin{array}{c}\text { Service } \\
\text { Frequency }\end{array}$ & $\begin{array}{c}\text { Number } \\
\text { of } \\
\text { (per hour) }\end{array}$ & \multicolumn{4}{|c}{$\begin{array}{c}\text { Population of the influence area } \\
\text { of the Station }\end{array}$} \\
\cline { 3 - 5 }$\sim 1$ & & \multicolumn{4}{c}{2000} & 2005 \\
\hline $1 \sim 2$ & 0 & 0 & 0 & 0 \\
$2 \sim 3$ & 11 & 0 & 0 & 0 \\
$3 \sim 4$ & 7 & 3,764 & 3,803 & 3,798 \\
$4 \sim 6$ & 32 & 2,909 & 2,875 & 2,833 \\
$6 \sim 12$ & 179 & 4,395 & 2,367 & 2,292 \\
$12 \sim$ & 206 & 4,507 & 4,483 & 4,660 \\
\hline Total & 435 & 4,484 & 4,724 & 4,799 \\
\hline
\end{tabular}

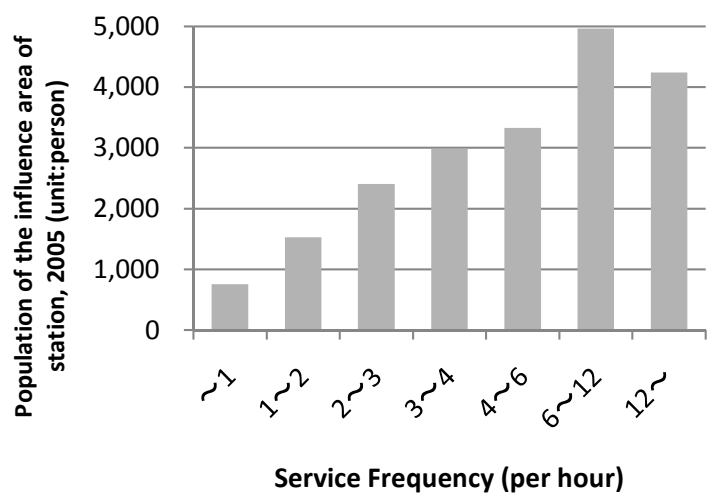

Figure 3: Population of the influence area of the station for each service frequency classification (all railway stations in cities).

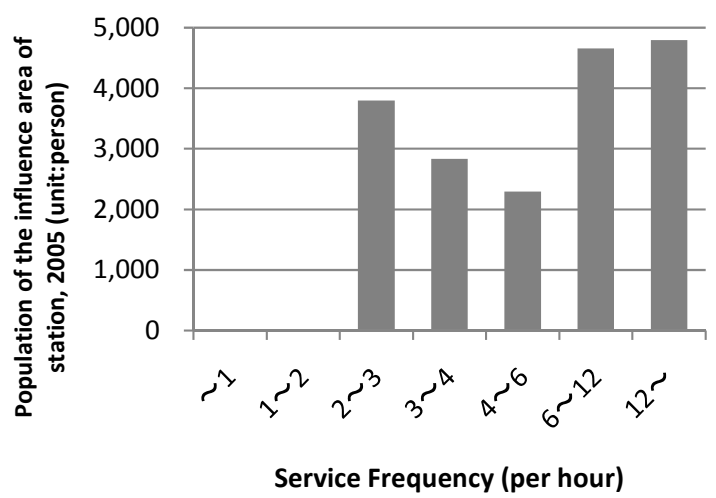

Figure 4: Population of the influence area of the station for each service frequency classification (all tramway stations in cities). 
differences in the populations of the influence area between the stations with service frequencies of 4-6/hour and those with service frequencies of 6-12/hour. Furthermore, in the case of tramways, the population of the influence area of stations with not so high service frequencies of 2-3/hour and 3-4/hour are rather large. These tramway stations include the stations in the neighbourhood of other railway stations and the stations around which other high frequent tramways are operated. So these factors are considered to push up the populations of the influence areas of the stations.

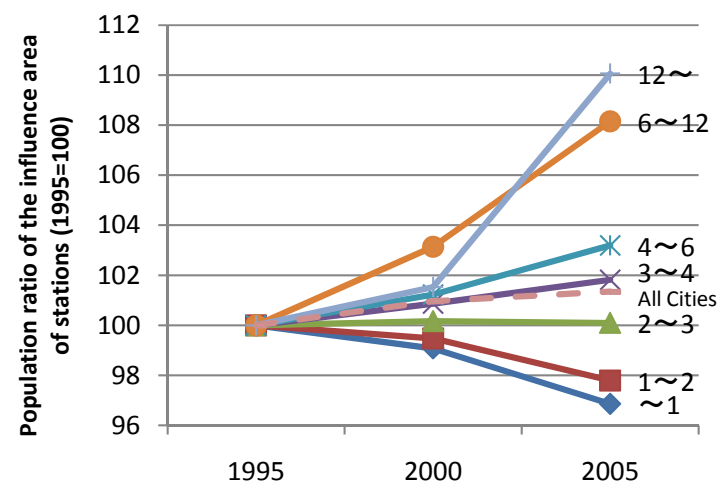

Figure 5: Changes of population of the influence area of stations for each service frequency classification over time (all railway stations).

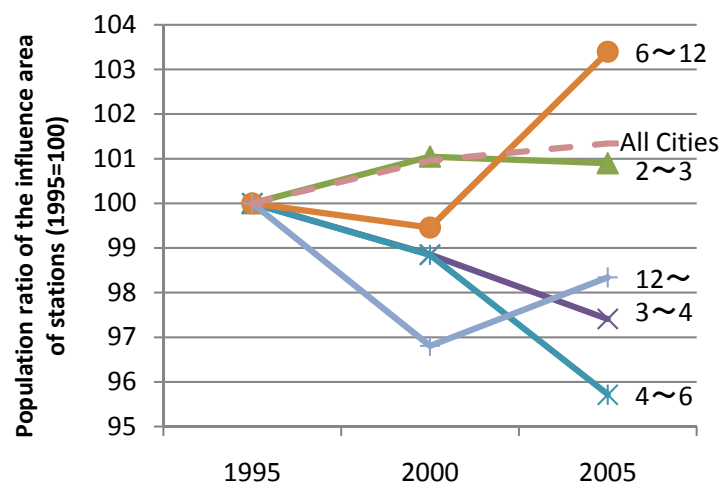

Figure 6: Changes of population of the influence area of stations for each service frequency classification over time (all tramway stations).

The populations of the influence areas of the stations have changed over time. As shown in Fig. 5, in the case of railway stations, the population per the influence area of the stations with service frequencies of 6-12/hour and more than 12 /hour has largely increased. In the case of railway stations, the higher the service frequency is, the larger the increase of population of the influence area of the station becomes. In the case of tramway stations, as shown in Fig. 6, the 
populations of the influence area of the station with service frequencies of 6 12/hour and more than 12/hour have decreased until 2000. However, since 2000, they have increased. On the other hand, the populations of the influence area of the station of tramway with service frequencies of less than $6 /$ hour tend to decrease.

\subsection{Relationship between distributions of population around railway and tramway stations within DID and service frequencies}

The populations of the influence area of stations within densely inhabited districts (hereinafter referred as DID) in 1995, 2000 and 2005 were calculated for each service frequency classification.

As shown in Table 3 and Fig. 7, in the case of railways, the higher the service frequency of the station is, the more the population of the influence area of the station tends to increase.

As shown in Fig. 8, the populations of the influence area of stations with service frequencies of less than $4 /$ hour decrease compared with the analysis of 4.1 above. Populations of the railway stations with a service frequency of $3 /$ hour

Table 3: Population of the influence area of stations for each service frequency classification (railway stations within DID).

\begin{tabular}{c|r|rrr}
\hline \multirow{2}{*}{$\begin{array}{c}\text { Service } \\
\text { Frequency }\end{array}$} & $\begin{array}{c}\text { Number } \\
\text { of } \\
\text { (per hour) }\end{array}$ & \multicolumn{3}{|c}{$\begin{array}{c}\text { Population of the influence area } \\
\text { of the Station }\end{array}$} \\
\cline { 3 - 5 }$\sim 1$ & Stations & 1995 & 2000 & 2005 \\
\hline$\sim 17$ & 2,040 & 2,010 & 1,944 \\
$1 \sim 2$ & 261 & 2,475 & 2,439 & 2,389 \\
$2 \sim 3$ & 273 & 2,985 & 2,971 & 2,971 \\
$3 \sim 4$ & 115 & 3,179 & 3,186 & 3,199 \\
$4 \sim 6$ & 208 & 3,377 & 3,414 & 3,483 \\
$6 \sim 12$ & 222 & 4,681 & 4,825 & 5,059 \\
$12 \sim$ & 23 & 3,967 & 4,016 & 4,338 \\
\hline Total & 1,179 & 3,237 & 3,259 & 3,308 \\
\hline
\end{tabular}

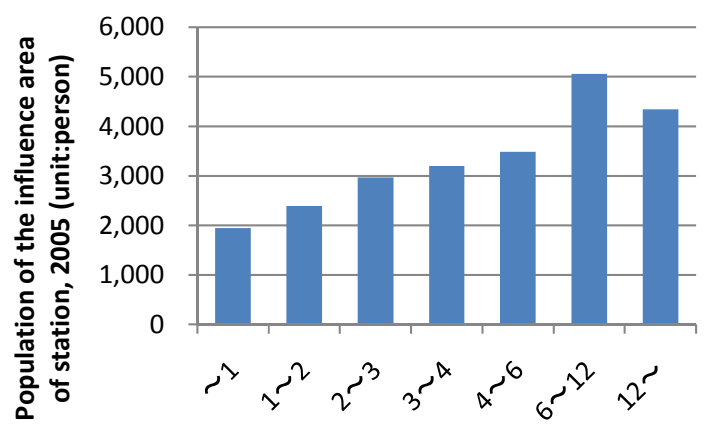

Service Frequency (per hour)

Figure 7: Population of the influence area of stations for each service frequency classification (railway stations within DID). 
or more go beyond the increase rate of all DID population. On the other hand, the populations of the influence area of stations with service frequency of less than $2 /$ hour fell below the increase rate of all DID population. From the above, even within DID, the populations around the stations with low service frequencies flow out, and the populations around the stations with high service frequencies remarkably tend to take roots and increase.

As shown in Table 4, in Figs. 9 and 10, all tramway stations excluding 14 stations exist in the DID, so there were no large differences from the analysis result of 4.1 .

\subsection{Evaluation of the compactness of cities}

This chapter is to verify whether the development of railways and tramways with high service frequencies could lead to increase the proportions of the populations around the stations to those of cities and total DID, and as a result could lead to the formation of compact cities.

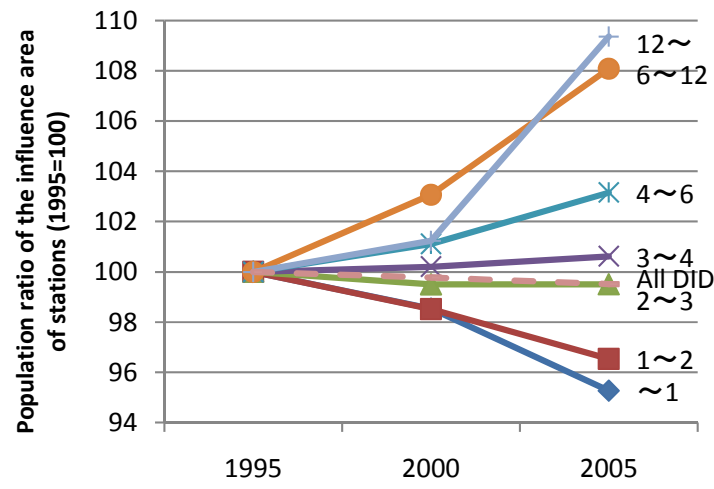

Figure 8: Change of population of the influence area of stations for each service frequency classification over time (railway stations within DID).

Table 4: Population of the influence area of stations for each service frequency classification (tramway stations within DID).

\begin{tabular}{c|r|rrr}
\hline Service & Number & \multicolumn{3}{|c}{$\begin{array}{c}\text { Population of the influence area } \\
\text { of the Station }\end{array}$} \\
\cline { 3 - 5 } (per hour) & $\begin{array}{c}\text { of } \\
\text { Stations }\end{array}$ & 1995 & 2000 & 2005 \\
\hline$\sim 1$ & 0 & 0 & 0 & 0 \\
$1 \sim 2$ & 0 & 0 & 0 & 0 \\
$2 \sim 3$ & 10 & 4,028 & 4,060 & 4,061 \\
$3 \sim 4$ & 7 & 2,909 & 2,875 & 2,833 \\
$4 \sim 6$ & 28 & 2,616 & 2,593 & 2,514 \\
$6 \sim 12$ & 170 & 4,664 & 4,627 & 4,808 \\
$12 \sim$ & 206 & 4,880 & 4,724 & 4,799 \\
\hline Total & 421 & 4,589 & 4,497 & 4,600 \\
\hline
\end{tabular}




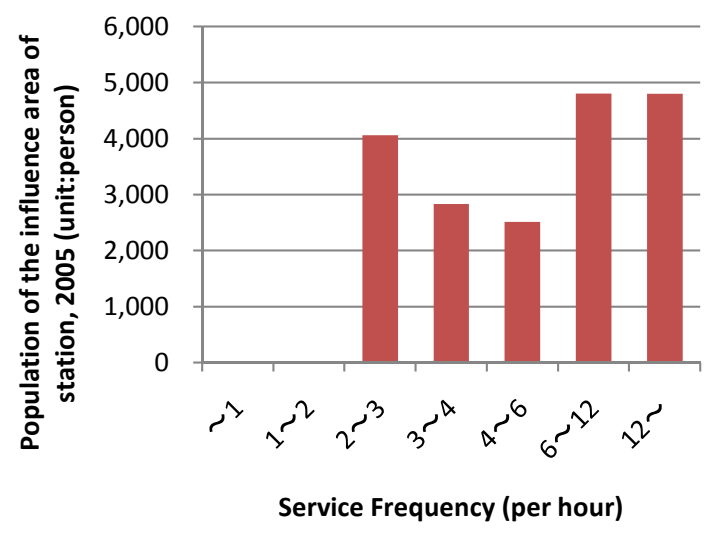

Figure 9: Population of the influence area of stations for each service frequency classification (tramway stations within DID).

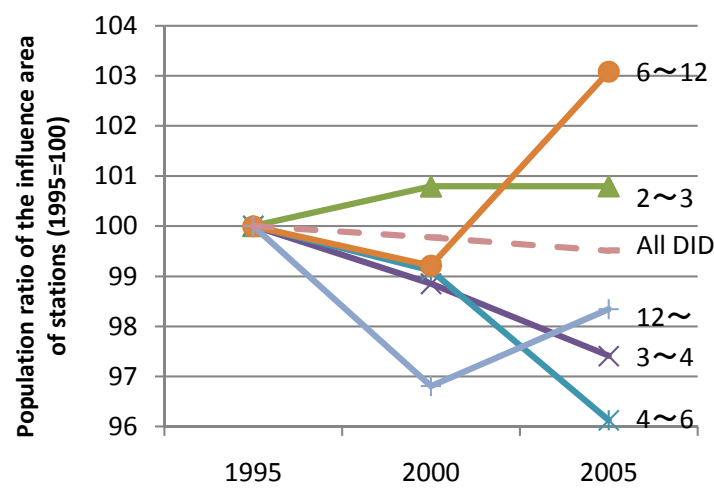

Figure 10: Change of population of the influence area of stations for each service frequency classification over time (tramway stations within DID).

To begin with, the railway stations were classified into those with service frequencies of $3 /$ hour or more and less than $3 /$ hour, and the proportions of the population in the radius of $500 \mathrm{~m}$ of stations to the total population of the city were calculated. As a result, as shown in Fig. 11, the proportions of population around the stations with service frequencies of higher than $3 /$ hour increased. However, the proportions of population around the stations with service frequencies of lower than 3/hour decreased. As shown in Fig. 12, the proportion of the population of the influence areas of stations with service frequencies of 3/hour or more, to the populations within DID around railway stations remarkably increased. 


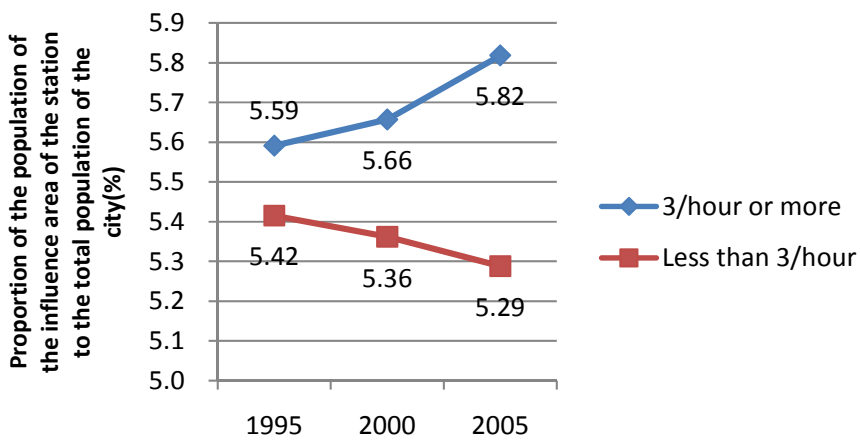

Figure 11: Proportion of the population of the influence area of the station to that of the city (all railway stations).

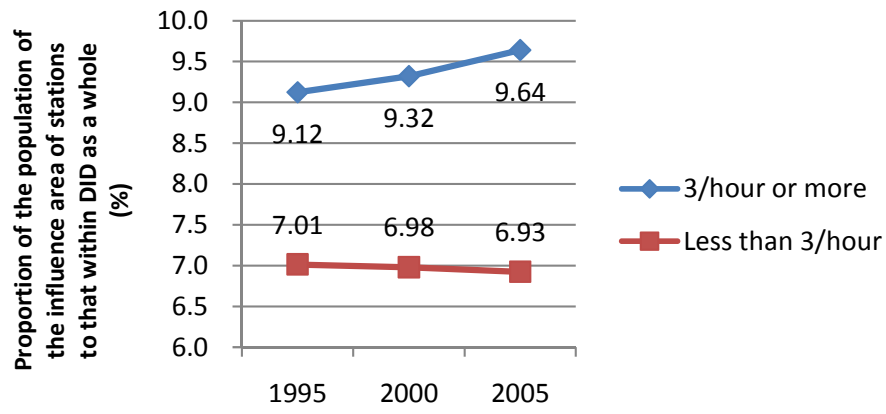

Figure 12: Proportion of the population of the influence area of the station to that of the city (railway stations within DID).

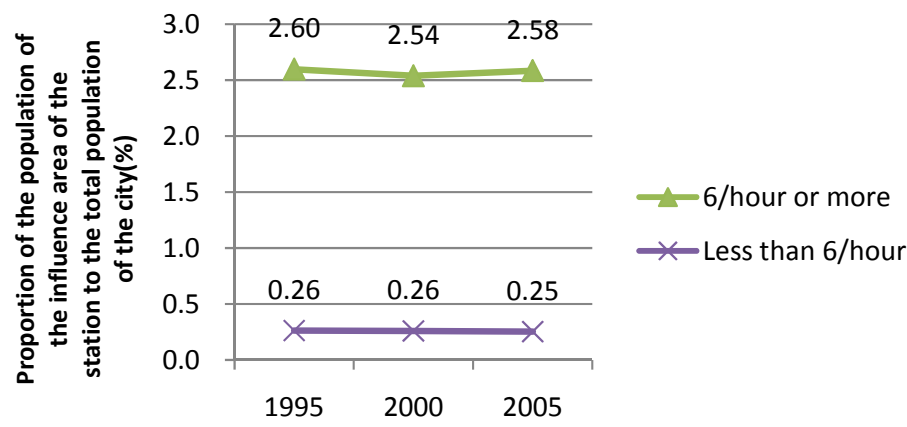

Figure 13: Proportion of the population of the influence area of the station to that of the city (all tramway stations). 
Then, the tramway stations were classified into those with their service frequencies of 6/hour or more and those of less than 6/hour, and the proportions of the population within the radius $500 \mathrm{~m}$ of stations to the total populations of city and DID was calculated, respectively. As a result, as shown in Figs. 13 and 14 , the proportions of the populations around the stations with service frequencies of $6 /$ hour or more have decreased since the year 2000. On the other hand, the proportions of populations around the stations with service frequencies of less than 6/hour have slightly decreased.

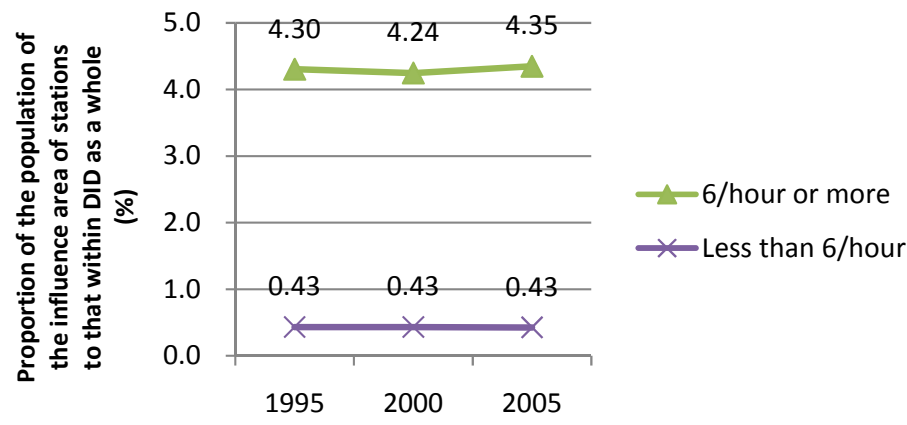

Figure 14: Proportion of the population of the influence area of the station to that of the city (tramway stations within DID).

\section{Conclusion}

This study analyzed the present distributions of populations around stations and how they have changed over time by the levels of service frequencies of railways and tramways in all local cities in Japan. As a result, generally, the populations of the influence area of stations with higher service frequencies are confirmed to become larger. As for the changes of the populations over time, it was clear the populations of the influence area of railway stations with a service frequency of $2-3 /$ hour or less tend to decrease, and the populations of the influence area of railway stations with higher service frequencies increase. Since 2000, the populations of the influence area of tramway stations with service frequencies of $6 /$ hour or more have increased. There is a difference in the boundaries of service frequencies to increase or decrease populations between railway stations and tramway stations. This is considered because the transport capacity of tramways is smaller than that of railways, and that tramway stations are relatively closer to the central parts of cities.

Even if the stations within DID are focused, it was clear that the populations of the influence area of stations with high service frequencies are large, and that the increasing rate of these populations is high as well.

It was clear that the proportion of the populations of the influence area of stations with high service frequencies to the total population of the city is increasing. 
From the above, it is clear that many people are living in the influence area of railway and tramway stations with high service frequencies in local cities in Japan and the populations are increasing, so this does in fact lead to the formation of compact cities.

\section{References}

[1] A. Mochizuki, D. Nakagawa \& T. Kasahara, Empirical analysis concerning the effect of Toyama Light Rail on the regional transport activities, Journal of the City Planning Institute of Japan, No.42-3, pp.949-954, 2007.

[2] T. Oba, S. Matsuda, A. Mochizuki, D. Nakagawa \& R. Matsunaka, Effect of Urban Railroads on the Land Use Structure of Local Cities, Urban Transport XIV: Urban Transport and the Environment in the 21st Century, pp.437-445, WIT press, 2008.

[3] Y. Miyata, K. Ando \& E. Yamamura, Measuring the Changes in the Regional Populations Caused by a Removal of Local Railways - A Stepwise Chow Test Approach -, Journal of the City Planning Institute of Japan, No.28, pp.643-648, 1993.

[4] D. Nakagawa, Y. Nishimura \& M. Hatoko, A Study on the Effect of the Introduction of Railways on the Changing of Population of Cities, Infrastructure Planning Review, No.11, pp.57-64, 1993.

[5] C. Hass-Klau \& G. Crampton, Future of Urban Transport - Learning from Success and Weakness: Light Rail -, Environmental and transport planning, 2002.

[6] H. Tsuji, K. Miyashita \& K. Takahashi, Study on Urban Forms in the Possession of Tramway, Journal of the City Planning Institute of Japan, No.34, pp.991-996, 1999.

[7] H. Sabo, Study on Compact Structure of Medium and Small Size Cities, Journal of

[8] K. Kaido, The Study of evaluation of urban-life environment by using population density indicator - Transportation and local facilities in the walking distance area -, Journal of the City Planning Institute of Japan, No.36, pp. 421-426, 2001. 